\title{
Investigation of Liquefaction Behaviour for Cohesive Soils
}

\author{
Mehmet Inanc Onur \\ Anadolu University \\ 2 Eylul Campus, Eskisehir, Turkey \\ mionur@anadolu.edu.tr
}

\begin{abstract}
The most frequently problem in the deformation of soils under dynamic effects is liquefaction. Detailed investigation on the liquefaction is required to take precautions against deformations caused by earthquakes. A good knowledge of the soil properties is necessary for the prediction of the liquefaction potential. However, it is thought that the liquefaction is limited with only sandy soils, recent studies have found susceptibility to liquefaction in silts, clays and gravels. Studies on the liquefaction criteria for cohesive soils have been continued. In this study, cohesive soils were tested by using laboratory scale shaking table to investigate liquefaction potential. Firstly, soil samples were taken from the city of Eskisehir, Turkey. In the results of the study; parameters on the liquefaction behaviour for cohesive soils were discussed. Cohesive soils with high clay amount do not let excessive pore water pressure, therefore liquefaction is not occurred but settlement and softening can be seen with dynamic loading.
\end{abstract}

Keywords: Liquefaction, Shaking Table Test, Cohesive Soils, Dynamic Loading.

\section{Introduction}

Liquefaction is occurred with the earthquakes and dynamic loading. Dynamic loads cause pore pressure development and effective stress decrease. Especially loose silty sand soils tend to liquefaction and show large soil deformations. Structural damages can be seen by liquefaction. Liquefaction is a complex problem in geotechnical earthquake engineering. The excess pore pressure development is the first stage of the liquefaction. If non-cohesive soils are saturated and rapid loading occurs excess pore pressure exist and effective stress will be zero. Liquefaction is divided into two main groups: flow liquefaction and cyclic mobility [1]. Cyclic mobility can occur under a large range of soil and site conditions than flow liquefaction. Flow liquefaction failures are characterized by the sudden nature of their origin but both flow liquefaction and cyclic mobility can produce damages. As a result of the liquefaction, settlement or overturning can be seen. Figure 1 shows the damage caused by liquefaction in the 1999 Kocaeli earthquake.

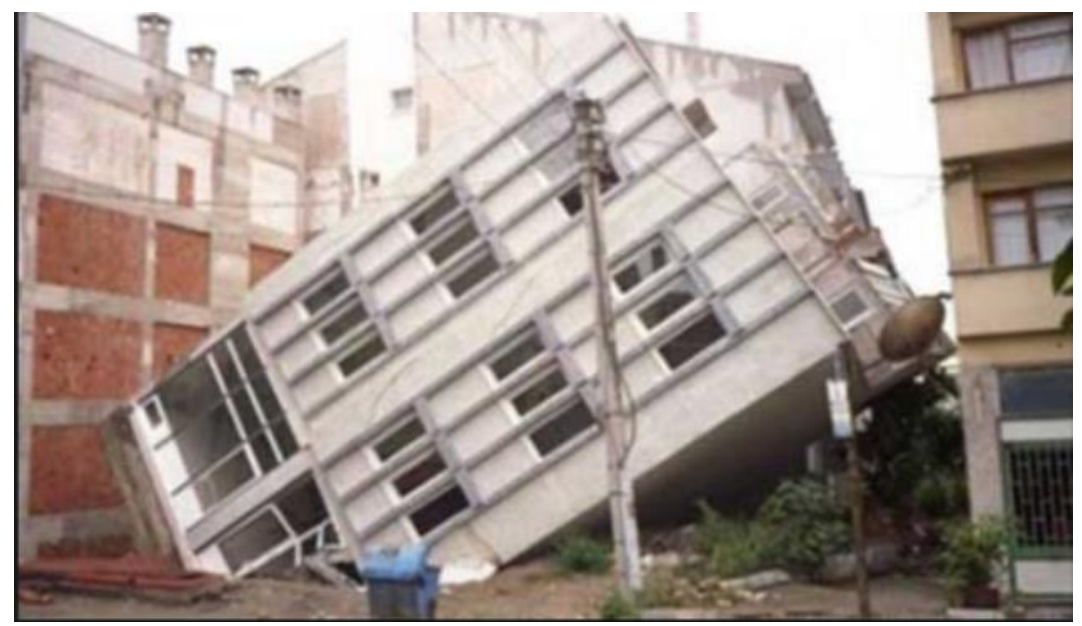

Fig. 1: An example of liquefaction damage. 
Geotechnical earthquake engineers must determine the liquefaction potential by investigating soil susceptibility, size of the dynamic trigger and size of possible damage. Liquefaction potential determination includes historical, geologic and compositional investigation [1]. Compositional properties associated with volume change potential, particle size, shape and gradation. Historical investigation includes data base research about liquefaction occurrence from past earthquakes.

Liquefaction potential can be determined by different methods. First one is based on the results of laboratory tests and the second one is methods based on in situ tests, in addition model tests can be used. Soil properties can be measured in large soil volumes by field tests. Although, laboratory experiments need less time and economy. Field tests classified as two main groups such as low deformation and large deformation tests. Low deformation field tests are seismic reflection, crosshole, downhole, seismic dilatometer etc and large deformation field tests are SPT and CPT. Low deformation laboratory test are resonant column, ultrasonic pulse and bender element, large deformation laboratory tests are dynamic triaxial, dynamic shear and torsional shear. Modelling tests are known as shaking table and centrifuge test.

Liquefaction potential of the soils must be determined to take precautions. First research about liquefaction was performed by Casagrande at 1930s. But, liquefaction studies were gained popularity with researches of Seed, Idriss and Ishihara at 1970s. Gratchev et al. [2] investigated the soil micro structure and liquefaction potential. Elgemal et al. [3] estimated the liquefaction potential by using numerical analysis. Yang and Elgamal [4] studied on a correlation between the soil permeability and liquefaction potential. Hwang et al. [5] investigated the loess tendency to liquefaction. Bird et al. [6] developed a numerical methodology about liquefaction potential and damage risks. Kevin et al. [7] found out a prediction methodology by using statistical data and 3D analysis on the liquefaction potential. Yuan and Tadunbu [8] derived a new formula for the deformations induced liquefaction by using numerical methods. Ishihara and Cubrinovski [9] showed the liquefaction phenomena after 1995 Kobe earthquake and soil density and compaction is found as key factor on the liquefaction. Thevanayagam and Martin [10] investigated the soil improvement methods against liquefaction and compaction methods were suggested at the end of the study. Yang and Sato [11] showed a relationship between liquefaction and earthquake movement in vertical and horizontal directions. Adalier and Elgamal [12] studied stone column method on liquefaction potential and positive results were found. Chang [13] developed a new field test to estimate liquefaction by measuring pore pressure and vibration. Yunmin et al. [14] studied the correlation between the shear wave velocity and liquefaction by using dynamic triaxial test.

A good knowledge of the soil properties is necessary for the prediction of the liquefaction potential. However, it is thought that the liquefaction is limited with only sandy soils, recent studies have found susceptibility to liquefaction in silts, clays and gravels. Studies on the liquefaction criteria for cohesive soils have been continued. Non-plastic silts were observed to liquefy during the tests and it was determined that the plasticity affected the liquefaction behaviour. Gravels are similarly determined as a result of the tests that are sensitive to liquefaction due to gradation. For clays, studies still continue. Sensitive clays can show softening and deformation like liquefied soils. In the past, the Chinese criterion for cohesive soils was interpreted with liquefaction potential due to grain size, liquid limit value and natural water content, but recent studies have shown that these values vary according to the soils. Especially, Chinese criterion re-evaluated with new limit values. In the new criteria, if clay amount less than $10 \%$ and the liquid limit is less than or equal to $32 \%$, the liquefaction can occur, if the clay content is more than $10 \%$ and the liquid limit value is greater than $32 \%$, liquefaction potential depends on the loading cycle. On the other hand, it was emphasized that when the clay content is more than $20 \%$, there is no liquefaction potential. For the range of $10 \%$ to $20 \%$, additional work is required and the behaviour changes depending on the plasticity.

In this study, cohesive soils were taken from the city of Eskisehir, Turkey. Reconstituted samples were tested by using laboratory scale shaking table test device. Liquefaction behaviour of the soil samples are determined and the test results were presented.

\section{Experimental Study}

In this study, cohesive soils were tested by using laboratory scale shaking table to investigate liquefaction potential. Shaking table is a test system to simulate earthquake loading. 


\subsection{Materials}

Cohesive silty clay soil samples were used for the experiments. Samples were obtained from the city of Eskisehir, Turkey. Eskisehir is located in the second-degree earthquake zone. Soil index and classification tests were performed according to the ASTM standards. Basic soil characteristics are given in Table 1.

Table 1. Basic soil characteristics of the test sample.

\begin{tabular}{|l|l|}
\hline Description & Result \\
\hline USCS & CL \\
\hline Amount of Gravel & $1 \%$ \\
\hline Amount of Sand & $15 \%$ \\
\hline Amount of Silt\& Clay & $84 \%$ \\
\hline Natural Unit Weight & $19,3 \mathrm{kN} / \mathrm{m}^{3}$ \\
\hline Liquid Limit & $40 \%$ \\
\hline Plastic Limit & $17 \%$ \\
\hline Plasticity Index & 23 \\
\hline Natural Water Content & $19,8 \%$ \\
\hline
\end{tabular}

\subsection{Test Equipment}

A laboratory scale shaking table test device was used for the tests. Earthquake loading can simulate and soil behaviour can be observed by the shaking table test device. The shaking table test device is shown in Figure 2 . The system is controlled by a computer and all inputs is given automatically.

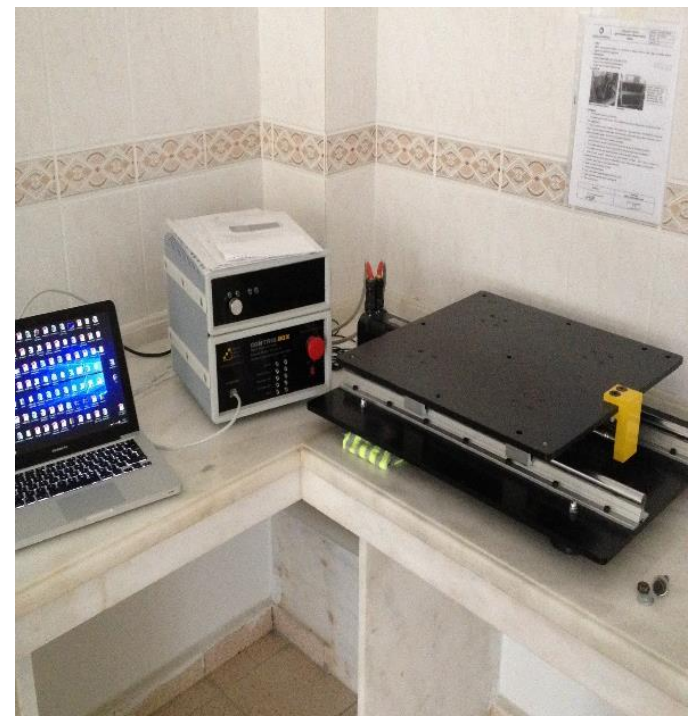

Fig. 2: Shaking table test device.

\subsection{Test Procedure}

A test program is prepared. Different acceleration and cycle is applied. Soils were put to the shaking table box without compaction. Ground water level is generally high (about at -3.00-meter depth) at Eskisehir so all soil profiles are considered fully saturated in the models. A vertical stress of $50 \mathrm{kPa}$ was applied to the surface of the soil by using a rigid mass. Test program is given in Table 2. 
Table 2: Test program.

\begin{tabular}{|c|c|c|}
\hline Test No & $\mathrm{a}\left(\mathrm{m} / \mathrm{s}^{2}\right)$ & $\mathrm{N}($ cycle $)$ \\
\hline 1 & 0.10 & 5 \\
\hline 2 & 0.30 & 5 \\
\hline 3 & 0.10 & 10 \\
\hline 4 & 0.30 & 10 \\
\hline
\end{tabular}

\section{Results}

Liquefaction tests were performed and the results are given in Table 3. Results show that excess pore water generation did not occur with the dynamic loading. But, different settlement amounts were observed. Cohesive soils do not let the water upward movement so excess pore water generation do not exit. On the other hand, cohesive soil show softening with the dynamic loading and soil grains are settled due to the applied vertical stress. Especially amount of settlement increases with number of cycle and acceleration.

Table 3: Test results.

\begin{tabular}{|c|c|}
\hline Test No & Result \\
\hline 1 & No pore water generation with $0,75 \mathrm{~cm}$ settlement \\
\hline 2 & No pore water generation with $1,85 \mathrm{~cm}$ settlement \\
\hline 3 & No pore water generation with $0,95 \mathrm{~cm}$ settlement \\
\hline 4 & No pore water generation with $2,25 \mathrm{~cm}$ settlement \\
\hline
\end{tabular}

\section{Conclusion}

Liquefaction is one of the major problem in geotechnical earthquake engineering. Liquefaction potential must be determined and safe solutions must be developed. Cohesive soils with high clay amount do not let excessive pore water pressure, therefore liquefaction is not occurred but settlement and softening can be seen with dynamic loading. Liquefaction potential should be determined by using much more tests. If the liquefaction potential is determined by different methods, soil improvement must be done. In addition, this study was performed for specific soil properties and dimensions. Size effect of the test set up and scale factor should be considered for the future studies.

\section{Acknowledgements}

This study was supported by Anadolu University Scientific Research Projects Commission under the grant no: 1705F331. Special thanks to Anadolu University Scientific Research Project Presidency.

\section{References}

[1] S. L. Kramer, Geotechnical earthquake engineering, Prentice Hall, 1996.

[2] I. B. Gratchev, K. Sassa, V. I. Osipov, V. N. Sokolov, "The liquefaction of clayey soils under cyclic loading," Engineering Geology, vol. 86, pp. 70-79, 2006. 
[3] A. Elgamal, Z. Yang, E. Para, "Computational modelling of cyclic mobility and post-liquefaction site response," Soil Dynamics and Earthquake Engineering, vol. 22, pp. 259-268, 2002.

[4] Z. Yang, A. Elgamal, "Influence of Permeability of Liquefaction-Induced Shear Deformation," ASCE, vol. 128, pp. 720-732, 2002.

[5] H. Hwang, L. Wang, Z. Yuan, "Comparison of liquefaction potential of loess in Lanzhou, China and Memphis, USA," Soil Dynamics and Earthquake Engineering, vol. 20, pp. 389-398, 2000.

[6] J.F. Bird, J.J. Brommer, H. Crowley, R. Pinho, "Modelling liquefaction-induced building damage in earthquake loss estimation," Soil Dynamics and Earthquake Engineering, vol. 26, pp. 15-26, 2005.

[7] M. Kevin, L. Dawson, G. Baise, "Three-dimensional liquefaction potential analysis using geostatistical interpolation," Soil Dynamics and Earthquake Engineering, vol. 25, pp. 369-380, 2005.

[8] D. Yuan, S. Tadunbu, "A practical numerical method for large strain liquefaction analysis of saturated soils," Soil Dynamics and Earthquake Engineering, vol. 24, pp. 251-265, 2004.

[9] K. Ishihara, M. Cubrinovski, "Characteristics of ground motion in liquefied deposits during earthquakes," Journal of Earthquake Engineering, vol. 9, pp. 1-16, 2005.

[10] S. Thevanayagam, G. R. Martin, "Liquefaction in silty soils-screening and remediation issues," Soil Dynamics and Earthquake Engineering, vol. 22, pp. 9-23, 2002.

[11] J. Yang, T. Sato, S. Savidis, X. S. Li, "Horizontal and vertical components of earthquake ground motions at liquefiable sites," Soil Dynamics and Earthquake Engineering, vol. 22, pp. 229-246, 2002.

[12] K. Adalier, A. Elgamal, "Mitigation of liquefaction and associated ground deformations by stone columns," Engineering Geology, vol. 72, pp. 275-291, 2004.

[13] W. Cheng, "Development of an in situ dynamic liquefaction test," Ph.D dissertation, Texas Uni., Austin, 2002.

[14] C. Yunmin, K. Han, C. Ren-peng, "Correlation of shear wave velocity with liquefaction resistance based on laboratory tests," Soil Dynamics and Earthquake Engineering, vol. 25, pp. 461-469, 2005. 